\title{
Viral subtype and heterosexual acquisition of HIV Original infections diagnosed in Scotland
} article

\author{
D L Yirrell, D J Goldberg, J Whitelaw, C McSharry, F Raeside, G Codere
}

Objective: As at December 1998, $87 \%$ of the estimated 33 million people living with HIV throughout the world resided in Africa and South East Asia. ${ }^{1}$ In Scotland (and the United Kingdom), a major public health concern has been that non-B subtypes of HIV which predominate in the regions above might enter the country and spread heterosexually among the indigenous population. The authors conducted an investigation to determine if, and to what extent, such transmission had occurred.

Methods: Stored blood samples from people who were diagnosed as HIV positive in central Scotland during 1995-7 and who were reported to have acquired their infection heterosexually, were identified. Sequence data were sought from each sample and, where obtained, viral subtype was assigned. For each case, viral subtype was linked to corresponding epidemiological details on heterosexual risk.

Results: Viral sequence was obtained from specimens for 53 of 59 cases. For 43 of the 53 cases, information on region of sexual contact was known. All 19 cases who had a sexual risk in Africa or Asia had a non-B subtype (A, C, or E) while 20 of 24 cases who did not report sexual contact in these regions had a B subtype $(\mathrm{p}<0.0001)$. Of the remaining 10 cases, nine had a subtype B and one a subtype $\mathrm{C}$ virus.

Conclusion: There is no evidence that non-B viral strains from developing countries have yet disseminated appreciably among indigenous heterosexual men and women within Scotland. Continuing to collect both demographic and molecular data from indigenous heterosexuals who are newly diagnosed with HIV would improve the chances of detecting rapidly any appreciable dissemination of non-B subtypes among this population if it were to occur. Such information would be helpful in informing HIV prevention strategies.

(Sex Transm Inf 1999;75:392-395)

Keywords: heterosexual transmission; HIV-1 subtypes; DNA sequencing; genotyping; Scotland

\section{Introduction}

To December 1998 UNAIDS estimated that throughout the world 33.4 million people were living with HIV. ${ }^{1}$ Of these, approximately 770000 were in Europe and central Asia, 890000 in North America, 1.4 million in South America, 6.7 million in south and South East Asia and 22.5 million in sub-Saharan Africa. The great majority of all cases are infected with HIV-1 and most of these have viruses which belong to the $\mathrm{M}$ (main) group, ${ }^{2}$ with the $\mathrm{O}$ (outlier) and newly described $\mathrm{N}$ (non-M, non-O) group accounting for very small numbers. ${ }^{3}$ On the basis of viral sequence data, the $\mathrm{M}$ group is further subdivided into 10 subtypes, denoted A-J, which have a broadly geographical distribution. ${ }^{4}$ Subtype B has predominated among infected people in western countries where the majority of infections have been acquired through injecting drug use and male homosexual intercourse. ${ }^{5}$ Although many other subtypes, notably A, C, D, and E, have been identified in Europe ${ }^{6-9}$ they are particularly common in developing regions such as sub-Saharan Africa and South East Asia where the principal route of transmission is heterosexual intercourse. ${ }^{10}$

In Scotland 2725 cases of HIV had been diagnosed to December $1997^{11}$ Forty two per cent were injecting drug users (IDUs), 32\% were homosexual/bisexual males, and $17 \%$ were men and women in whom infection was attributed to heterosexual intercourse. Of the 469 heterosexuals, 164 probably acquired their HIV abroad (including 124 from Africa and 10 from Asia) and 138 had a high risk partner (including 123 with an IDU partner and 10 a bisexual male partner). For 87, no further information was available and for 80 , no high risk partner could be identified and infection probably occurred in the United Kingdom.

A major public health concern has been that people travelling between Scotland (and the rest of the United Kingdom) and Africa and Asia could bring into Scotland non-B strains of HIV which might then spread heterosexually among the wider population. ${ }^{12}{ }^{13}$ While there is ample evidence to indicate that HIV infected IDUs and homosexual/bisexual males in Scotland harbour the subtype B strain, ${ }^{14}$ hitherto, there were no HIV strain data for individuals who probably acquired their infection heterosexually. Accordingly, it was unknown if imported infection from these regions had seeded into the indigenous heterosexual population of Scotland. The investigators set out to link strain and demographic data on heterosexually infected individuals who had been diagnosed in Scotland in recent years.

\section{Methods}

BACKGROUND

Since 1985 HIV testing laboratories throughout Scotland have reported cases of HIV 
seropositivity to the Scottish Centre for Infection and Environmental Health (SCIEH). ${ }^{15}$ Reporting is near $100 \%$ complete and the information held on each case includes sex, date of birth, soundex code of surname, first part of postal code of residence, date of earliest positive specimen, and risk category; these data are collected through the use of a national HIV request form. Where heterosexual intercourse is the only risk activity indicated, an active system of surveillance is implemented to gather additional information and verify the probable route of transmission. A letter is written to the patient's attending physician asking specific questions to determine if the cases or any of their sexual partners belonged to a high risk category and if they or their partners had sexual exposure abroad; up to $25 \%$ of cases are recategorised as IDUs or homosexual/bisexual males.

In Scotland, 154 people who were categorised as probably having acquired their HIV infection through heterosexual intercourse had an earliest positive specimen between 1 January 1995 and 31 December 1997. Of these, 55 were diagnosed in Lothian Health Board (includes Edinburgh), 41 in Greater Glasgow, 22 in Tayside (includes Dundee), and 36 in the rest of Scotland.

\section{OBJECTIVES}

(1) To identify a single, stored blood sample from each of a selection of patients, diagnosed as HIV positive during 1995-7, who had been recorded on the SCIEH database as having probably acquired their infection through heterosexual intercourse.

(2) To ascertain the HIV subtype in each sample.

(3) For each patient, to link the details of viral subtype with corresponding epidemiological information on heterosexual risk.

SAMPLE SELECTION

Eligible individuals were restricted to those who (a) met the criterion as indicated in objective (1) above, and (b) were undergoing clinical follow up in either Edinburgh or Glasgow because over $60 \%$ of heterosexual cases in Scotland were from these two areas; furthermore, immunology laboratories in both cities were able to provide blood specimens which were residual following routine CD4 count analysis.

In Edinburgh, an aliquot of plasma from all CD4 count specimens is cryopreserved routinely; this practice allowed specimens for virtually all cases who were diagnosed HIV positive in this city during $1995-7$ to be obtained. In Glasgow residual plasma specimens were not cryopreserved routinely. Accordingly, small aliquots $(1 \mathrm{ml})$ of residual whole blood were collected prospectively from all eligible cases who had a routine specimen taken during March and April 1998. Since the Glasgow component of the study had to be prospective, the opportunity was taken to collect whole blood, rather than plasma. Plasma samples are less likely to yield sequence data than whole blood because (a) the viral
RNA is more labile than proviral DNA, and (b) the in vitro conversion of RNA to cDNA, catalysed by reverse transcriptase, is inefficient.

\section{DATA LINKAGE}

Lists of eligible patients (date of birth, sex, soundex code, and a unique numerical identifier) were given to co-investigators at the respective immunology laboratories. Stored specimens from Edinburgh and prospectively collected specimens from Glasgow, bearing only their unique identifying number, were sent to the Centre for HIV Research at the University of Edinburgh for sequencing. Each result, with its corresponding code, was then sent to SCIEH so that it could be matched with its corresponding demographic and risk information. The study was covered by ethics committee approval which had been given to perform viral sequencing of HIV in residual specimens from infected patients throughout Scotland.

\section{LABORATORY METHODS}

Viral RNA and proviral DNA were extracted from plasma and whole blood samples respectively. The RNA was subjected to reverse transcription to produce cDNA. Proviral DNA and cDNA were then amplified by nested polymerase chain reaction (PCR) in the p17 region of the gag gene (and in some cases additionally in the $v 3 / v 4$ region of the env gene) and sequenced directly on an ABI 373A automated sequencer as described elsewhere. ${ }^{16}$ The resulting sequences were aligned using the GDE package and then neighbour joining phylogenetic trees were constructed, using reference subtype strains from international databases as comparisons, so that a viral subtype could be assigned to each case. ${ }^{17}$

\section{Results}

SAMPLES

From the 55 identified patients from Lothian Health Board, stored plasma specimens were located for 48 and sequence material from the gag region was obtained in 42 of these. Of the 41 identified patients from Greater Glasgow, 11 whole blood samples were obtained and all yielded gag sequence data.

\section{SUBTYPE ASSIGNATION}

The 53 gag sequences were compared by phylogenetic analysis with homologous sequences from international databases and assigned to subtype (table 1$)$. Twenty three $(43 \%)$ of the specimens examined were HIV-1 subtypes other than $\mathrm{B} ; 17$ were subtype $\mathrm{C}$ and six subtype A. No other gag subtypes were identified. However, since subtype $\mathrm{E}$ is a recombinant virus with a subtype A gag gene, further sequencing of gag subtype $\mathrm{A}$ viruses in the $\mathrm{v} 3 / \mathrm{v} 4$ region of the env gene (data not shown) was performed to differentiate between true A and $\mathrm{E}$ subtypes. This further analysis revealed that one was indeed subtype $\mathrm{E}^{18}$

\section{ASSOCIATION OF SUBTYPE WITH CONTACT DATA} (TABLE 2)

Details of viral subtype were linked with corresponding epidemiological information on 
Table 1 Viral subtype assignation by gag sequence

\begin{tabular}{llllr}
\hline & \multicolumn{4}{l}{ Subtype } \\
Health board area & $B$ & Non- $B$ & $A$ & \multicolumn{1}{c}{ A } \\
\cline { 2 - 5 } Lothian & 26 & 16 & $4(1 \mathrm{E})$ & 12 \\
Greater Glasgow & 4 & 7 & 2 & 5 \\
Total & $30(57 \%)$ & $23(43 \%)$ & 6 & 17 \\
\hline
\end{tabular}

Table 2 Association of subtype with geographical origin of infection

\begin{tabular}{|c|c|c|c|c|c|}
\hline \multirow[b]{2}{*}{ Reported sexual contact } & \multicolumn{4}{|c|}{ Viral subtype } & \multirow[b]{2}{*}{ Total } \\
\hline & $A$ & $B$ & C & $E$ & \\
\hline With IDU in UK or rest of Europe & $1^{\star}$ & 8 & 0 & 0 & 9 \\
\hline \multicolumn{6}{|l|}{ Not with IDU } \\
\hline in UK only & 0 & 8 & $2 \dagger$ & 0 & 10 \\
\hline in Europe (ex UK) only & 0 & 3 & 1 & 0 & 4 \\
\hline in USA & 0 & 1 & 0 & 0 & 1 \\
\hline in sub-Saharan Africa & 4 & 0 & 13 & 0 & 17 \\
\hline in Asia & 0 & 0 & 1 & 1 & 2 \\
\hline in many countries (unspecified) & 0 & 1 & 1 & 0 & 2 \\
\hline No information & 0 & 8 & 0 & 0 & 8 \\
\hline Total & 5 & 29 & 18 & 1 & 53 \\
\hline
\end{tabular}

*Reported sexual contact with IDU in Austria.

†One Zambian national reporting no risk outside UK, one sexual contact with African partner in the UK.

heterosexual risk for the 53 cases of whom 18 (seven from Greater Glasgow and 11 from Lothian) were female. For eight cases, all of whom had a B subtype, no information was available. Two cases, one who had a $\mathrm{B}$ and the other a C subtype, reported sexual risk in many, unspecified, countries. Of the nine cases who reported sexual contact with an IDU (in the United Kingdom or elsewhere in Europe), eight had a B and one an A subtype; this latter case indicated sexual contact with an IDU in Austria. Of the remaining 34 cases, 10 (eight with $\mathrm{B}$ and two with $\mathrm{C}$ subtype) reported sexual contact only in the United Kingdom, four (three with $\mathrm{B}$ and one with $\mathrm{C}$ subtype) contact outside the United Kingdom but only in Europe, 17 (13 with $\mathrm{C}$ and four with A subtype) contact in sub-Saharan Africa, two (one with $\mathrm{C}$ and one with $\mathrm{E}$ subtype) contact in Asia, and one (B subtype) contact in the United States.

Both cases who had subtype $C$ viruses which were reportedly acquired in the United Kingdom had an African connection; one was a Zambian national who claimed not to have been sexually active before his arrival in Scotland and the other had sexual contact with an African partner in the United Kingdom. Seventeen cases almost certainly acquired their $\mathrm{HIV}$ in sub-Saharan African countries which included Zambia, Botswana, and Uganda. The two isolates from Asia were from India (subtype C) and Thailand (subtype E), a finding which is consistent with what is known about the prevalent subtypes in these countries. Indeed, the only non-B subtype for which no country of origin was specified was a subtype $\mathrm{C}$ virus. A comparison of this with other subtype $\mathrm{C}$ viruses from around the world grouped it with isolates from India (data not shown) thus suggesting this to be the likely region where the infection was acquired.

For 43 cases, information on region of sexual contact was known. All the 19 cases who reported sexual risk in Africa or Asia had a
non-B subtype while 20 of 24 cases who did not report sexual contact in Africa or Asia had a B subtype. This association was highly significant $(p<0.0001$, Fisher's exact test).

\section{Discussion}

A recent survey of $211 \mathrm{HIV}$ infected IDUs and homosexual/bisexual males living in the northern part of the United Kingdom and Ireland demonstrated that all had subtype $B$ infection. ${ }^{14}$ To ascertain the extent to which non-B subtypes had entered Scotland, and on the understanding that, worldwide, most non-B infections are spread through heterosexual intercourse, the study was restricted to those infected people who had reported this activity as their only risk of infection. While the 53 cases sequenced were not necessarily representative of HIV infected heterosexuals throughout Scotland, they comprised 34\% $(53 / 154)$ and $55 \%(53 / 96)$ of all cases diagnosed in Scotland and central Scotland respectively during 1995-7.

Just over half of the cases investigated had a subtype B strain and, where information was available, heterosexual risk was confined to the United Kingdom, United States, or Europe. Thus, in this series of cases, molecular typing to distinguish $\mathrm{B}$ from non-B subtypes was shown to be highly predictive of the region (developed or developing world) where HIV was probably acquired. This is an important finding because in instances where risk and demographic information cannot be obtained from the patient, molecular data can assist in tracing the likely origins of infection. No information was available from eight of the 53 cases and since they were all subtype $\mathrm{B}$, the chances of them having been infected outside the United Kingdom, United States, or Europe are low.

If, as this study suggests, non-B subtypes have not disseminated into Scotland's heterosexual population it is not because people infected with non-B subtypes have only come to Scotland recently. Indeed, HIV infected heterosexuals in Scotland who acquired their infection in Africa have been a potential source of HIV since the mid to late 1980s; between 1985 and 1990, 37 cases were diagnosed in central Scotland, the area covered by this study. It is possible that some dissemination has occurred but, as yet, remains undetected since HIV infected heterosexuals tend to be tested for HIV serostatus at a relatively late stage of their HIV disease..$^{19}$ A possible explanation for the lack of dissemination is that there has been insufficient heterosexual mixing between those infected in either Africa or Asia and indigenous people for cultural reasons and/or the transient nature of the former group's stay in Scotland.

To date, those who have been most at risk of acquiring HIV heterosexually in Scotland have been the sexual partners of IDUs. During the late 1980s and the 1990s, however, needle/ syringe exchange programmes reduced the spread of HIV among IDUs and thus the risk of HIV transmission from them to their partners. ${ }^{20-22}$ Few cases of heterosexual transmission in Scotland have occurred among 
females who have had sex with an infected bisexual man. It would therefore seem reasonable to predict a decline in the number of HIV transmissions among Scotland's indigenous heterosexual population. However, the global prevalence of HIV is continuing to increase and together with the ever increasing frequency of foreign travel, it is possible that these factors might alter the dynamics of HIV transmission among heterosexual men and women in Scotland (and the rest of the United Kingdom) in the future.

Continuing to collect both demographic and molecular data from indigenous heterosexuals who are newly diagnosed with HIV would improve our chances of detecting rapidly any appreciable dissemination of non-B subtypes among this population if it were to occur. Such information would be helpful in informing HIV prevention strategies.

This work was funded in part by a grant from the University of Edinburgh Moray Endowment Fund.

Contributors: DY designed the project, performed the viral Contributors: DY designed the project, performed the viral
subtyping, and wrote the paper; DG designed the project and subtyping, and wrote the paper; DG designed the project and
wrote the paper; $\mathrm{CMcS}$ and JW provided the samples for testing wrote the paper; $\mathrm{CMcS}$ and JW provided the samples for testing
and wrote the paper; FR and GC performed the epidemiologiand wrote the paper; FR and GC performed the epidemiological investigations to ascertain risk factor information,
heterosexual transmission, and wrote the paper.

1 UNAIDS. Global summary of the HIV/AIDS epidemic, December 1998. Geneva: Joint United Nations Programm on AIDS, 1998

Workshop report from the European Commission (DGXII INCO-DC) and the Joint United Nations Programme on HIV/AIDS. AIDS 1997;11:UNAIDS17-36.

3 Simon F, Mauclere P, Roques P, et al. Identification of a new human immunodeficiency virus type 1 distinct from group $M$ and O. Nat Med 1998;4:1032-7.

4 Korber BTM, Foley B, Kuiken C, et al. Human retroviruses and AIDS: a compliation and analysis of nucleic acid and amino acid sequences. and Biophysics Group, Los Alamos National Laboratory, 1997.
5 Expert Group of the Joint United Nations Programme on HIV/AIDS. Implications of HIV variability for transmission: scientific and policy issues. AIDS 1997;11: UNAIDS1-15.

6 Arnold C, Barlow KL, Parry JV, et al. At least five HIV-1 sequence subtypes (A,B,C,D,A/E) occur in England. AIDS Res Hum Ret 1995;11:427-9.

7 Clewley JP, Arnold C, Barlow KL, et al. Diverse HIV-1 genetic subtypes in UK. Lancet 1996;347:1487.

8 Barin F, Courouce A-M, Pillonel J, et al and the Retrovirus Study Group of the French Society of Blood Transfusion. Increasing diversity of $\mathrm{HIV}_{\mathrm{M}}$ serotypes in French blood Increasing diversity of $\mathrm{HIV}_{\mathrm{M}}$ serotypes in French blood donors over 8 .

9 Alaeus A, Leitner T, Lidman K, et al. Most HIV-1 genetic subtypes have entered Sweden. AIDS. 1997;11:199-202.

10 Mastro TD, Kunanusont C, Dondero TJ, et al. Why do subtypes segregate among persons with different risk behaviours in South Africa and Thailand? AIDS 1997;11:11316.

11 Goldberg D, Allardice G, McMenamin J, et al. Monitoring HIV infection and HIV disease progression in Scotland. Health Bull 1998;56:645-7.

12 Balfe P. The changing face of the HIV epidemic: new rules and new problems. SGM Ouarterly 1998;25:54-5.

13 Scott G, Goldberg D, Weir M, et al. HIV prevalence among heterosexuals attending genitourinary clinics in Scotlandheterosexuals attending genitourinary clinics in
the African connection. BMF 1997;315:1281-2.

14 Leigh-Brown AJ, Lobidel D, Wade CM, et al. The molecular epidemiology of HIV type 1 in six cities in Britain and Ireland. F Virol 1997;235:166-77.

15 Goldberg DJ, Emslie JA, Smyth W, et al and collaborating microbiologist. A system for surveillance of voluntary HIV testing; results of the first 2 years, 1989-1990. AIDS 1992; 6:495-500.

16 Yirrell DL, Robertson P, Goldberg DJ, et al. Molecular investigation into outbreak of HIV in a Scottish prison. BMF 1997;314:1446-50.

17 Yirrell DL, Pickering H, Palmarini G, et al. Molecular eidemiological analysis of HIV in sexual networks in Uganda. AIDS 1998;12:285-90.

18 McCutchan FR, Salminen MO, Carr JK, et al. HIV-1 genetic diversity. AIDS 1996;10(supp1 3):S13-20

19 CD4 Collaborative Group. CD4 surveillance in Scotland: perspectives on severe HIV-related immunodeficiency. AIDS 1997;11:1509-17.

20 Frischer M, Elliott L, Taylor A, et al. Do needle exchanges help to control the spread of HIV among injecting drug users? AIDS 1993;7:1677-8.

21 Taylor A, Frischer M, Green ST, et al. Low and stable prevalence of HIV among Glasgow drug injectors. Int $\mathcal{F}$ STD AIDS 1994;5:105-7.

22 Des Jarlais D, Hagan H, Friedman SR, et al. Maintaining low HIV seroprevalence in populations of injecting drug users. $7 A M A$ 1995;274:1226-31. 